\title{
Consumer Acceptance on Chocolate Drink Made with a Mixture of Commercial Cocoa Powder and Unfermented Cocoa Powder
}

\author{
Laras Cempaka $^{1 *}$, Tubagus Emir Abdul Hakim ${ }^{1)}$, and Wahyudi David ${ }^{1)}$ \\ ${ }^{1)}$ Department of Food Science and Technology, Universitas Bakrie \\ Jl. H.R. Rasuna Said Kav C-22, Kuningan, Jakarta, Indonesia \\ ${ }^{*}$ Corresponding author: laras.cempaka@bakrie.ac.id \\ Received: 18 May 2021 / Accepted: 06 August 2021
}

\begin{abstract}
Cocoa is one of the foods that contains polyphenol-rich compounds that act as antioxidants. The processing of cocoa into chocolate products generally causes a decrease in the number of polyphenols. In the development of chocolate beverage products, it is necessary to evaluate sensory evaluation. The purpose of this study was to determine consumer acceptance, total phenolic content (TPC) and antioxidant activity (AA) of chocolate drinks made from commercial cocoa powder added with unfermented cocoa beans. Seventy-five panelists (17-23 years) contributed to the consumer acceptance of one benchmark and four samples of chocolate drinks with a ratio of commercial cocoa powder: unfermented cocoa beans $=100 \%$ : 0 , 90\%: $10 \%, 80 \%: 20 \%, 70 \%: 30 \%$, respectively. Then the sample was analysed for its total phenolic content using the Folin-Ciocalteau method and antioxidant activity using the ascorbic acid equivalent antioxidant capacity (AEAC). The results showed that the sample with a composition of $100 \%$ commercial fermented cocoa had the highest value on each sensory attribute. It had the highest TPC, antioxidant activity, and inhibition percentage value of $321.235 \mathrm{mg}$ GAE, $982.19 \mathrm{ppm}$ and $46 \%$, respectively. The addition of the unfermented cocoa beans composition showed a decrease in the level of consumer preference. However, the addition did not significantly affect the total phenolic content, but slightly increased the antioxidant activity. The use of unfermented cocoa beans for adding the main ingredient that are not processed with appropriate cocoa processing standards has not been well received by consumers, so proper processing of unfermented cocoa beans is required if the polyphenol compound is desired.
\end{abstract}

Keywords: antioxidant, cocoa, chocolate, drink, unfermented cocoa beans

\section{INTRODUCTION}

Cocoa beans are the main ingredient in making chocolate products and contain polyphenols which act as antioxidants that have benefits for human health (Andujar et al., 2012; Urbanska et al., 2019). Polyphenolic compounds in nature are classified into flavonoids and nonflavonoids. Polyphenols are synthesized by plants and widely distributed in the tissues, where they mainly exist in form of glycosides. In detail, polyphenols are well- known group of phenolic systems characterized by at least two phenyl rings and one or more hydroxyl substituent (Singla et al., 2019).

In cocoa, polyphenol compounds were mostly dominated by flavonoid groups consisting of about $58 \%$ proanthocyanidin groups, $37 \%$ flavan-3-ol/flavanols, $4 \%$ anthocyanidins and $1 \%$ flavonol glycosides (Hii et al., 2009; Jalil \& Ismail, 2008). Polyphenol compounds in cocoa and its derivative products have various 
health benefits, namely as antioxidants, boost the immune system, prevent endocrine and cardiovascular diseases, anti-inflammatory, anti-cancer, and prevent dental caries (Recio et al., 2012). The polyphenol content and composition of cocoa depends on the genotype, origin, growing conditions, degree of pod maturity, and the processing of cocoa from the beans to the semi-finished product and the final cocoa product (Urbanska et al., 2019).

Besides as antioxidants, polyphenols influence sensory attributes such as colour and taste (Shahidi \& Ambigaipalan, 2015). The cocoa bean processing, such as fermentation is often considered to be the factor that causes the reduction of several polyphenol content (Sudibyo, 2017; Delgado-Ospina et al., 2020). During the fermentation process, there are microbes contained in cocoa beans that contribute the biochemical changes process. The presence of metabolic activity and an increase in temperature can evaporate polyphenol compounds, so that there is a decrease in polyphenol content (Sabahannur et al., 2018; Suazo et al., 2013).

Cocoa processing can improve the colour and taste of products that are preferred by consumers. However, along with processing accompanied by heating, it will certainly reduce the functional content of cocoa. The use of cocoa without fermentation can retain the polyphenol content but produces a flavour that consumers do not like. However, not only fermentation can reduce the functional content of cocoa beans, but also various processes such as drying, roasting and other processes that use heat energy (Racine et al., 2019; Urbanska \& Kowalska, 2019).

Products from processed cocoa consist of semi-finished ingredients as well as products that are ready for consumption. Semi-finished cocoa products include cocoa butter, cocoa powder and cocoa liquor (Afoakwa, 2014). Cocoa bean is processed into ready-to-eat products, for example, cakes, cookies, bakery, and confectionary products (Ramlah, 2016).

Processed cocoa products such as chocolate drinks are very popular products for all ages (Hii et al., 2009). Beverage manufacturers always add chocolate in menu as a preferred choice. However, cocoa products often use other additional raw materials that are considered less healthy for consumers, such as sugar and creamers made from animal ingredients (Aprotosoaie et al., 2016). Therefore the appropriate formulation is needed in order the chocolate drinks can still be accepted by consumers but still safe for health.

This study examined the chocolate drink with unfermented cocoa powder raw materials and the composition of ingredients that are considered healthier. The purpose of this study was to determine the level of consumer acceptance, total phenolic content and antioxidant activity of chocolate drinks made from a mixture of commercial cocoa powder and unfermented cocoa powder, and their relationship.

\section{MATERIALS AND METHODS}

This research was conducted from June to August 2019 at the Sensory Laboratory, Bakrie University. The analysis of total phenolic content was carried out at the Laboratory of the Post-Harvest Center, Bogor, and analysis of the antioxidant activity were carried out at the Laboratory of Biopharmaca, Bogor Agricultural University. There were four formulations and one benchmark product (BM) as control used in this study. Each formulation has a different ratio of commercial fermented cocoa powder and unfermented cocoa powder. Table 1 shows the formulation of chocolate drinks. Control is cocoa commercial product, while F1, F2, F3, and F4 are $100 \%, 90 \%$, 
$80 \%$ and $70 \%$ fermented cocoa powder, respectively. Unfermented cocoa powder is processed manually as the following steps: cocoa beans are roasted at $150^{\circ} \mathrm{C}$ for 35 minutes. The beans are peeled from the shell, then milled. Pressed, and the cake was growed and sieved using a 60 mesh sieve. The results obtained are fine unfermented cocoa powder. Furthermore, the cocoa powder can be mixed with other ingredients in the formulation.

The ingredients used in the manufacture of cocoa drinks are non-fermented cocoa powder obtained from Sumedang Small and Medium Entreprises (SMEs), fermented cocoa powder, vegetable creamer, stevia sweetener and vanilla flavour. In this study, a commercial product (control) product is used as a comparison product that has been sold in the market, namely cocoa powder. The composition of benchmark product is not presented here to deal with company's privacy.

\section{Experiment Analysis}

Seventy-five naive panellists (university students between 19 and 23 years of age) evaluated the sensory attributes by using hedonic test. The attributes cover the colour, aroma, taste, aftertaste, and overall acceptance. The test was accomplished based on the 9-point hedonic scale by panellist and scaled as $1=$ dislike extremely, 2 = dislike very much, $3=$ dislike moderately, $4=$ dislike slightly, $5=$ neither like nor dislike, $6=$ like slightly, $7=$ like moderately, $8=$ like very much, and $9=$ like extremely. All samples with three-digit code were analyzed by panelists. Each sample change, panelists were asked to rinse their mouth with mineral water, before testing other samples.

Analysis of total phenolic levels was carried out according to Mustafa et al. (2010). The ethanol extract of the $0.10 \mathrm{~mL}$ drink sample and $0.50 \mathrm{~mL}$ of Folin-Ciocalteau solution were added to $0.90 \mathrm{~mL}$ distilled water. The mixture was then vortexed and incubated for 5 minutes. The mixture was then given $2.50 \mathrm{~mL}$ of $7 \% \mathrm{Na}_{2} \mathrm{CO}_{3}$ and vortexed followed by incubation for 26 minutes at room temperature. After incubation, the absorbance of the solution was measured at a wavelength of $755 \mathrm{~nm}$. The procedure was replicated two times for another batch. The standards used in this test were gallic acid standards with concentrations of 50,100, $150,200,250,300,350$, and $400 \mu \mathrm{g} \cdot \mathrm{mL}^{-1}$.

Analysis of antioxidant activity was carried out according to Moharram \& Youssef (2014). Measurement of antioxidant activity was carried out using the 2,2-Diphenyl1-picrylhydrazyl (DPPH) method. The DPPH method is an accurate simple, fast and easy for screening the radical scavenging activity of several compounds. As much as $0.750 \mathrm{~mL}$ of sample extracts at different concentration was added to $1.50 \mathrm{~mL} \mathrm{DPPH}$ methanolic solution, and measured by a spectrophotometer UV-VIS at $517 \mathrm{~nm}$, inhibitory concentration 50\% (IC50) values expressed as $1 \mathrm{~g} . \mathrm{mL}^{-1}$ were determined by linear regression analysis of the results obtained at different

\begin{tabular}{lccccc}
\multicolumn{1}{l}{ Table 1. Chocolate drink formulation } & \multicolumn{1}{l}{} \\
\hline Formulation & Control & F1 & F2 & F3 & F4 \\
\hline Fermented cocoa powder $(\mathrm{g})$ & Instant chocolate & $4.2(100 \%)$ & $3.78(90 \%)$ & $3.36(80 \%)$ & $2.94(70 \%)$ \\
Non fermented cocoa powder $(\mathrm{g})$ & drink (sugar, cocoa & $0(0 \%)$ & $0.42(10 \%)$ & $0.84(20 \%)$ & $1.26(30 \%)$ \\
Stevia sweetener $(\mathrm{g})$ & powder, non dairy & 2.2 & 2.2 & 2.2 & 2.2 \\
Vegetable creamer $(\mathrm{g})$ & creamer, thickener, & 8.5 & 8.5 & 8.5 & 8.5 \\
Flavour (g) & nature identical vanilin & 0.1 & 0.1 & 0.1 & 0.1 \\
Water & flavour, salt) & 85 & 85 & 85 & 85 \\
\hline Total & & 100 & 100 & 100 & 100 \\
\hline
\end{tabular}

Notes: $\quad \mathrm{C}=$ control, F1 $=100 \%: 0 \%, \mathrm{~F} 2=90 \%: 10 \%, \mathrm{~F} 3=80 \%: 20 \%, \mathrm{~F} 4=70 \%: 30 \%$. 
concentrations of the sample. The procedure was replicated for another batch.

Sensory evaluation results were tested statistically through Analysis of Variance (ANOVA) using SPSS v16.1 software and Multidimensional Scaling (MDS) analysis using XLSTAT software version 2019. The ANOVA test was performed to determine whether there were significant differences between each sample. If there is a significant difference between each sample, then it is continued with Duncan's test to find out which treatment has a significant effect on the parameters of analysis. The significant differences were considered if $p<0.05$, and the results were expressed as mean values \pm standard deviations

In this study, MDS is used to determine the similarity and dissimilarity of a variable depicted in geometric space. The output is a map or configuration at the map point (Kruskal, 1977; Borg \& Groenen, 2005). MDS was carried out to see the similarity of the attributes of each sample with the commercial products. MDS analysis is classified into two classes: metric and nonmetric. MDS metrics are used for interval data or ratio scales with the aim of calculating distances in determining the position of a sample. Meanwhile, non-metric MDS is used for nominal or ordinal data for the purpose of ranking and showing a significant order of proximity (Domanoglu, et.al, 2018). In this study, the data was obtained in the ordinal form regarding the level of acceptance of the panelists. So, the MDS is performed to obtain positioning among the sample and benchmark.

In this study, the data was obtained in the ordinal form regarding the level of acceptance of the panelists. So, the MDS is performed to obtain positioning among the sample and benchmark.
The stress value is used to determine the adequacy of the number of dimensions obtained from the results of the MDS analysis. The stress value is a measure of the difference between the real multi-dimensional (p-dimensional) model and the reduced (k-dimensional) estimated space, which is desirable if it is below 0.025 . The stress value (Kruskal, 1977) used to determine the number of dimensions can be calculated using the following equation (Equation 1).

Stress-1 $=\sqrt{\frac{\sum\left(d_{i j}-\widetilde{d}_{{ }^{\prime}}\right.}{\sum d^{2}{ }_{i j}}} \ldots \ldots .$. Equation 1 dij; differences between i. and j. points.

If the stress level of a data is 0.00 , the validity level is perfect, 0.025 is very good, 0.05 is good, 0.1 is sufficient, and 0.2 is bad (Kruskall, 1977). The antioxidant activity with represent inhibition presentation and total phenolic content were analysed using linear regression using XLstat version 2019.

One sample student's t-test was used to test the hypothesis. A t-test is any statistical hypothesis test which follows a student's $\mathrm{t}$ distribution, if the null hypothesis is supported. It is most commonly applied when the test statistic would follow a normal distribution if the value of a scaling term in the test statistic is known. The one sample $\mathrm{t}$-test requires that the dependent variable follow a normal distribution. $5 \%$ of the t-tests one-tailed probability level was selected to signify the differences between the preferences. When the scaling term is unknown and is replaced by an estimate based on the data, the test statistic (under certain conditions) follows a student's t distribution (Chao, 2017). The t-test is used to find out whether the unknown means of two populations differ from each other based on the independent samples from each population. Samples were obtained from two or more different treatments. 
This test is only valid for comparing the mean of quantitative variables (Skaik, 2015).

\section{RESULTS AND DISCUSSION}

\section{Overall Consumer Acceptance}

Based on an assessment of all chocolate drink products with the addition of commercial fermented cocoa powder and unfermented cocoa powder, it describes the closest position distance from commercial products (benchmark) that are considered have similarity to one another. In Figure 1, it can be seen that the MDS results for the overall preference of the product have stress level of 0.1925 so that it can be said that the results obtained are still acceptable. Fermented cocoa powder $80 \%$ has a similarity with sample of $70 \%$ where the two are in the same quadrant and located close to the proximity matrix value of 0.400 . This is reinforced by the results of the hedonic test (Table 2) which shows that fermented cocoa powder $80 \%$ and $70 \%$ samples do not have significant differences in all the attributes tested. Samples in one quadrant have similar characteristics, while products contained in different quadrants have different characteristics (Andriani et al., 2018). It is described that there are no samples that are located in one quadrant with commercial products (control). Thus, It can be concluded that no samples as a whole have similarities with control.

Commercial cocoa powder is made by separating the fat in the form of cocoa butter through a pressing process. The result is a pressed cake which is processed through the stages of grinding, cooling and mixing so that it becomes cocoa powder. This cocoa

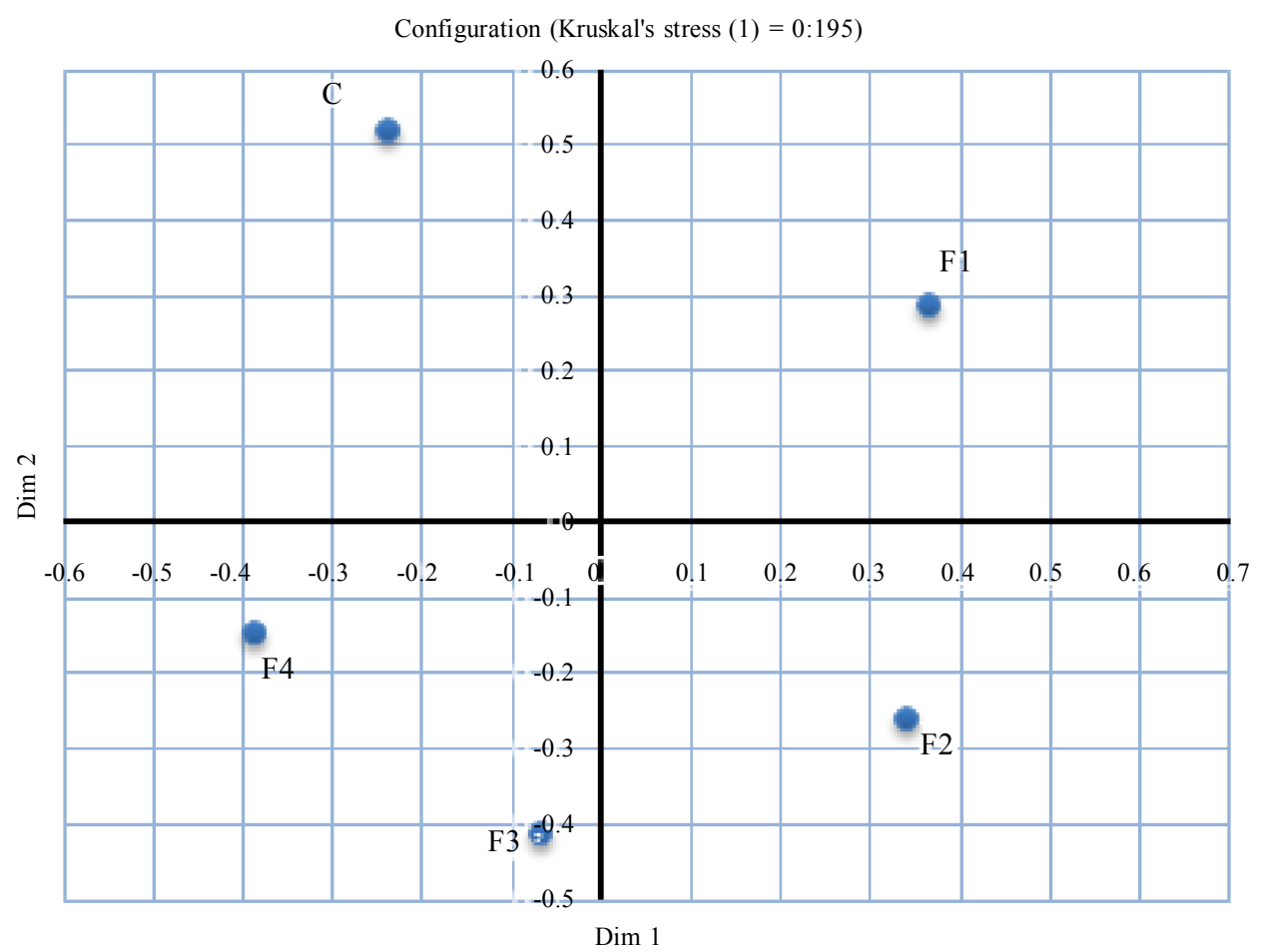

Figure. 1. Two dimensional results of similarity with Multidimensional Scaling (MDS), C = control, $\mathrm{F} 1=100 \%: 0 \%, \mathrm{~F} 2=90 \%: 10 \%, \mathrm{~F} 3=80 \%: 20 \%, \mathrm{~F} 4=70 \%: 30 \%$ (fermented cocoa powder: unfermented cocoa powder) 
Consumer acceptance on chocolate drink made with a mixture of commercial cocoa powder and unfermented cocoa powder

Table 2. Sensory evaluation results on chocolate drink formulations

\begin{tabular}{lccccc}
\hline Sample & \multicolumn{1}{c}{ Colour } & Flavor & Taste & Aftertaste & Overall \\
\hline Control & $6.22 \pm 1.5^{\mathrm{a}}$ & $6.92 \pm 1.47^{\mathrm{c}}$ & $6.36 \pm 1.94^{\mathrm{b}}$ & $5.98 \pm 1.82^{\mathrm{b}}$ & $<5.98 \pm 18^{\mathrm{b}}$ \\
F1 & $6.97 \pm 1.23^{\mathrm{b}}$ & $6.61 \pm 1.33^{\mathrm{bc}}$ & $5.89 \pm 1.92^{\mathrm{ab}}$ & $5.62 \pm 2.01^{\mathrm{ab}}$ & $5.62 \pm 2.01{ }^{\mathrm{ab}}$ \\
F2 & $6.61 \pm 1.13^{\mathrm{ab}}$ & $6.32 \pm 1.38^{\mathrm{ab}}$ & $5.73 \pm 1.6^{\mathrm{a}}$ & $5.44 \pm 1.65^{\mathrm{ab}}$ & $5.44 \pm 1.65^{\mathrm{ab}}$ \\
F3 & $6.28 \pm 131^{\mathrm{a}}$ & $6.04 \pm 1.64^{\mathrm{a}}$ & $5.42 \pm 1.72^{\mathrm{a}}$ & $5.32 \pm 1.61^{\mathrm{a}}$ & $5.32 \pm 1.61^{\mathrm{a}}$ \\
F4 & $6.17 \pm 1.34^{\mathrm{a}}$ & $6.08 \pm 1.55^{\mathrm{a}}$ & $5.48 \pm 179^{\mathrm{a}}$ & $5.34 \pm 1.62^{\mathrm{a}}$ & $5.34 \pm 1.76^{\mathrm{a}}$ \\
\hline Notes: & Numbers followed by different letters on each row indicate significantly different $(\mathrm{p}<0.05) ; \mathrm{C}=$ control, F1 $=100 \%: 0 \%$. \\
& F2 =90\%:10\%, F3 = 80\%:20\%, F4 = 70\%:30\% (Fermented cocoa powder: Unfermented cocoa beans).
\end{tabular}

powder is difficult to wet and dissolves in water, so we need a wetting agent that can homogenise and improve the texture. for example, in cocoa powder lecithin which contains 5\% soy lecithin. Lecithin can enhance these properties by its action as a wetting agent. $5 \%$ of soya lecithin is intensively mixed with cocoa powder and the resulting lecithinated powder is agglomerated with sugar. This gives so-called instant cocoa, which can be put directly into cold milk (Biehl \& Ziegleder, 2003). This commercial cocoa powder has a complete processing to produce consumeroriented chocolate products, which results in sensory attributes that are in accordance with consumer acceptance.

\section{Sensory Attributes}

Based on Table 2, the highest score on the colour attribute is observed in $100 \%$ fermented cocoa powder. This score is significantly different from the control product (control). In other formulations, the level of preference was not significantly different from control, with that of 70 and $80 \%$ fermented cocoa powder. This shows that the use of unfermented cocoa powder does not significantly change the level of preference for the colour attribute. However, the higher the percentage of unfermented cocoa powder, the lower the colour preference. Based on Figure 2 and Figure. 3, consumers prefer light colours over dark colours.

In the aroma attribute, control has the highest score. In general, the addition of unfermented cocoa powder decreased the preference for aroma with a significant difference ( $p<0.05$ ), but not with samples 70 and $80 \%$ fermented cocoa powder. In this attribute, samples with the $100 \%$ commercial cocoa powder formulation had the highest scores among the other samples.

The level of acceptance of after-taste in commercial products has the highest value of the four samples with an average value of 5.98 (rather like). Among the samples, which showed a higher aftertaste acceptance rate was in the $100 \%$ sample addition of commercial cocoa powder. From these results, it can be assumed that control products have better after-taste than the four treatments.

Based on the ANOVA results there was no significant difference between the four treatments $(p>0.05)$. Fermented cocoa powder $90 \%$ had the highest value compared to the other two samples, $80 \%$ and $70 \%$ fermented cocoa powder with a value of 5.44 . The overall acceptance rate for commercial products has the highest value of the four samples with an average value of 5.98 (rather like). From these results, it can be assumed that control products have overall the most favoured by the panellists than the four samples.

The conclusion from the hedonic test (Table 2) showed that the formulation of cocoa drinks with sugar and creamer substitutions, namely stevia and vegetable creamer, has sensory attributes whose scores are not much different from the comparing product, although statistically, it has a significant 


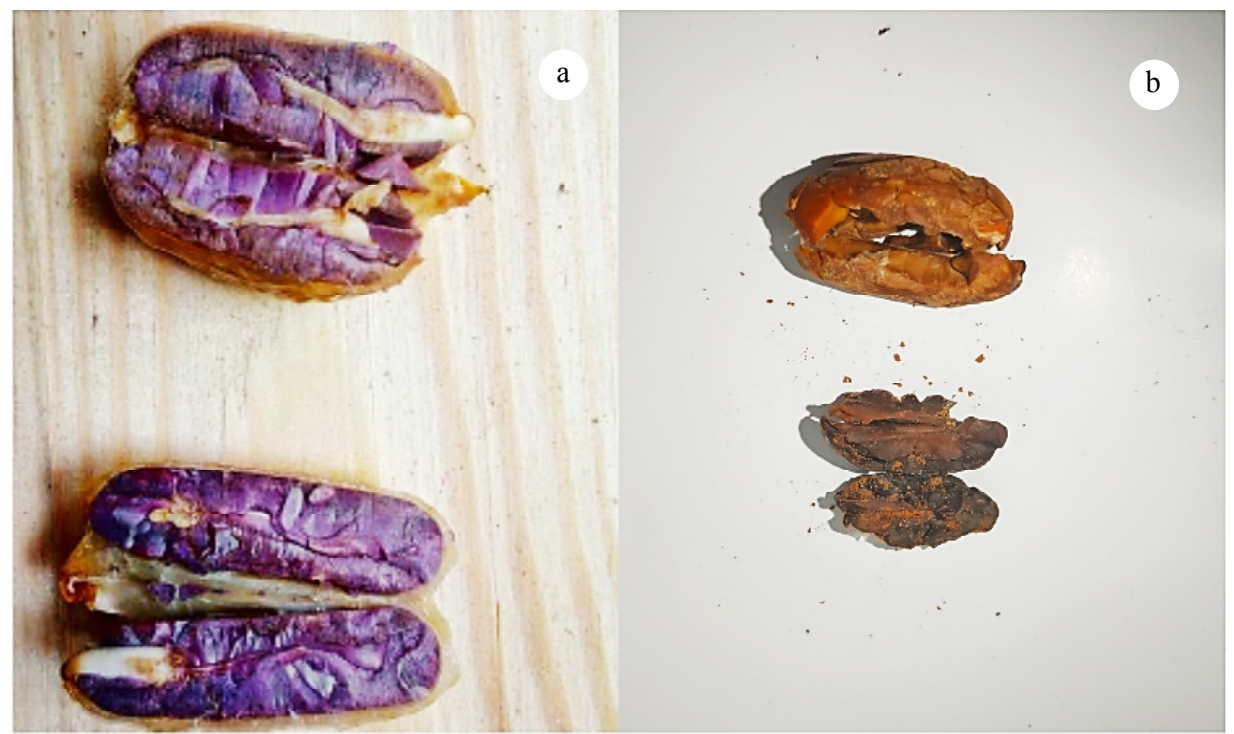

Figure 2. Colour differences of cocoa beans: a. unfermented beans and b. fermented beans

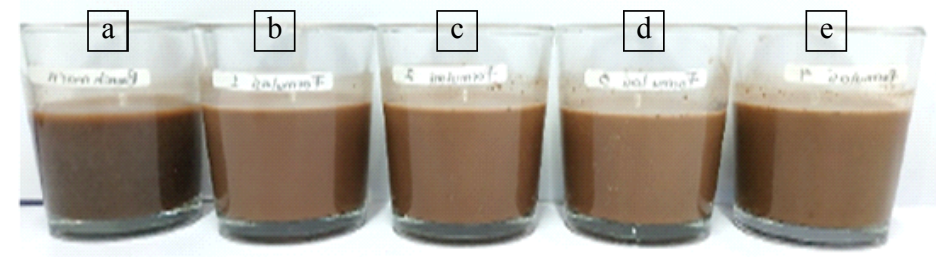

Figure 3. Colour differences in chocolate drink formulations: a. $\mathrm{C}=$ control, b. F1 $=100 \%: 0 \%$, c. F2 $=90 \%: 10 \%$, d. F3 = 80\%:20\%, and e. F4 =70\%:30\% (Fermented cocoa powder: Unfermented cocoa beans).

difference. If there is an addition of cocoa powder without fermentation, then the score for each attribute will decrease significantly with the addition of the amount of cocoa powder. However, with better processing, it is possible to produce cocoa drinks that are more acceptable to consumers (Purba et al., 2018).

\section{Total Phenolic Content}

From the results of the total phenolic content (TPC) test, the highest value was obtained in $100 \%$ with a value of $321.24 \pm 18.41$ mg GAE (Table 3). Based on Brcanovic et al. (2013), the range of TPC values for commercial cocoa powder is between 3.82-36.87 (mg. $\mathrm{g}^{-1}$ GAE. From the TPC regression equation with a low $\mathrm{R}^{2}$ shows insignificant values between formulations (Figure 4). The addition of cocoa powder without fermentation is considered to increase the TPC value of the sample. However, in this study, this has limited evidence due too the an edequate sampling representation. This can occur due to imperfect processing without a separation process between cocoa butter and cocoa powder, causing the composition of chocolate drinks to be less suitable (Langkong et al., 2020).

The results of the study showed that chocolate drink with the addition of unfermented cocoa powder did not contain a higher polyphenol content than fermented cocoa powder. The decrease in the content 
of polyphenol compounds during fermentation is due to the oxidation of polyphenols by the polyphenol oxidase enzyme, the diffusion of polyphenols from the cotyledons to the skin layer and the polymerization of polyphenol compounds, especially epicatechins and proanthocyanidins, to formed tannins and the formation of complexes with proteins and polysaccharides (Afoakwa et al., 2012).

\section{Antioxidant Activity}

Antioxidant activity is expressed as a percentage of inhibition, which is how many radical compounds (DPPH) can be inhibited by the antioxidant compounds found in chocolate drinks. The inhibition value of radical compound activity, the absorbance value of chocolate drinks was also compared with the standard in the form of ascorbic acid (vitamin C) to see its equivalence. This comparison value is expressed in the ascorbic acid equivalent antioxidant capacity (AEAC) in ppm units. The AEAC value for chocolate drinks can be seen in Table 3 .

From the results of the AEAC value, it was found that $100 \%$ fermented cocoa powder had the highest value (982 ppm) compared to other samples. However, in samples with the addition of cocoa powder without fermentation, the higher the addition, the higher the AEAC value. This indicates that the addition of cocoa without fermentation increases the level of antioxidant activity. However, based on the results of the regression analysis, the AEAC value between treatments was not different. The non-signiciant evidence seem to be because of limited sampling replications. In $100 \%$ fermented cocoa powder formulation, it can be seen that there are similarities in the values of TPC and AA with $70 \%$ formulation. It is possible that the fermented cocoa powder used has a high polyphenol content because the samples used come from two different sources, for fermented cocoa powder obtained from commercial cocoa powder samples, while unfermented cocoa powder are processed manually.

The results of testing for antioxidant activity in sample $100 \%$ fermented cocoa powder can inhibit free radicals by $46 \%$, and the least $90 \%$ fermented cocoa powder by $18 \%$. The results of the $t$ test showed a value of 0.683 , which indicates that there is no correlation between the TPC and the AEAC, value (Figure 4). The non-significant results need further finding in context of sampling replication. There should be a correlation between the two, as the research of Kumar et al. (2014) stated that there is a positive correlation between the antioxidant capacity of cocoa powder and their derivative products and the total number of polyphenols content. Therefore the lower the polyphenol content, the lower the value of its antioxidant activity. Processing of cocoa such as fermentation, drying, roasting and other processes will reduce the polyphenol content, so it tends to decrease its antioxidant activity. In this study, the commercial fermented cocoa powder is processed through a series of processes from cocoa beans into cocoa powder using steps that comply with cocoa processing standards. In addition, in the processing of unfermented cocoa powder, it was roasted at a temperature of $150^{\circ} \mathrm{C}$ for 35 minutes. The results of the study by Afoakwa et al. (2012) show that roasting greatly affects the polyphenol content of unfermented cocoa liquor. The higher the roasting temperature, the lower the polyphenol content of the cocoa paste produced. The results of Ramlah (2016) show that the roasting temperature of fermented cocoa beans affects the polyphenols and the resulting chocolate flavour. Therefore further research is needed to prepare unfermented cocoa powder that is processed according to cocoa bean processing standards. 
Table 3. Total phenolic content of each chocolate drink formulation

\begin{tabular}{lc}
\hline Fermented cocoa powder $(\%)$ & Total phenolic content (mg GAE) \\
\hline 100 & $321 \pm 18^{\text {a }}$ \\
90 & $258 \pm 35^{\text {a }}$ \\
80 & $305 \pm 24^{\text {a }}$ \\
70 & $280 \pm 30^{\text {a }}$ \\
\hline Notes: & GAE (gallic acid equivalents); numbers followed by different letters on each row indicate significantly different \\
& $(\mathrm{p}<0.05)$.
\end{tabular}

Table 4. Antioxidant activity value of each chocolate drink formulation

\begin{tabular}{ll}
\hline Fermented cocoa powder $(\%)$ & AEAC $(\mathrm{ppm})$ \\
\hline 100 & $982 \pm 16.5^{\mathrm{b}}$ \\
90 & $587 \pm 88.2^{\mathrm{a}}$ \\
80 & $631 \pm 181.8^{\mathrm{ab}}$ \\
70 & $889 \pm 140.4^{\mathrm{ab}}$ \\
\hline Notes: & AEAC (ascorbic acid equivalent antioxidant capacity); Numbers followed by different letters on each row indicate
\end{tabular}
significantly different $(\mathrm{p}<0.05)$

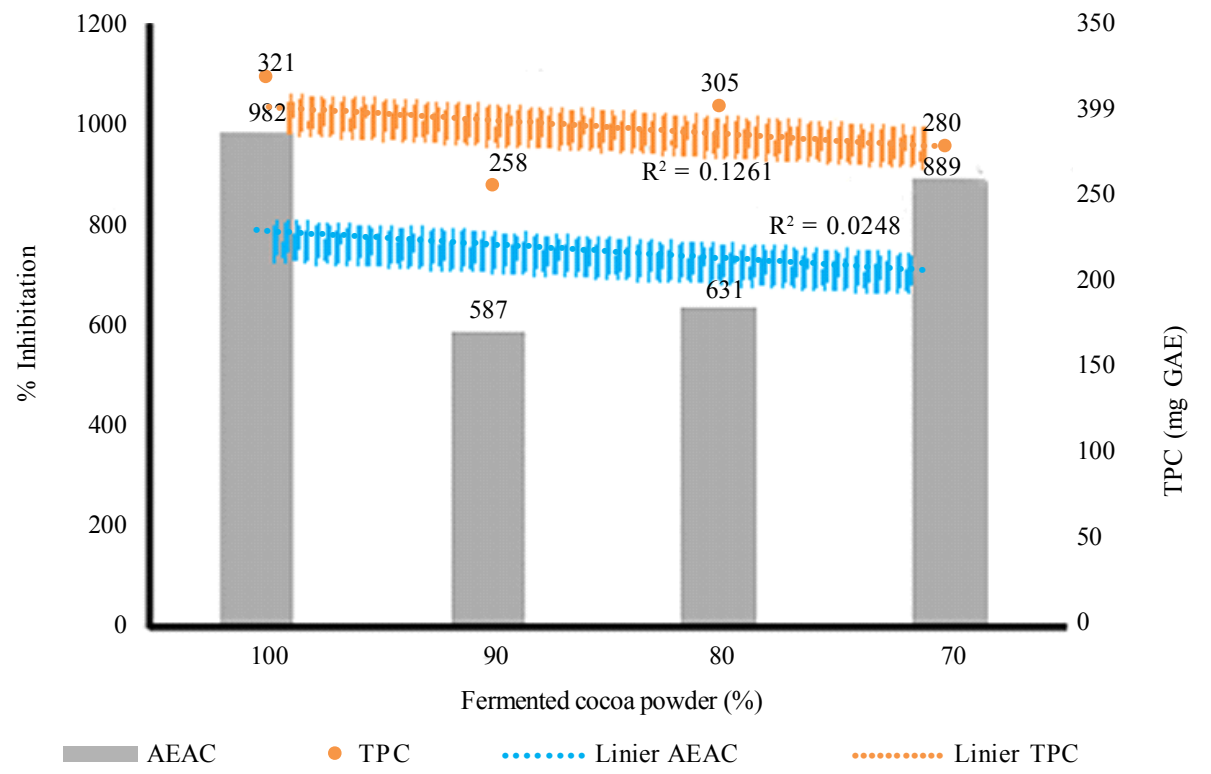

Figure 4. Regression analysis of total phenolic content and inhibition percentage and fermented cocoa powder

\section{CONCLUSIONS}

The hedonic test results show that samples with $100 \%$ commercial cocoa powder have a preferred color compared to other samples. For flavour, taste, aftertaste and overall attributes, each sample was not significantly different. With the addition of cocoa powder without fermentation, it causes a darker colour, which is less preferred by consumers. Based on the MDS, the sample with the addition of 20 and $30 \%$ cocoa powder unfermented has similarities with that of two samples which in the same quadrant and located close to the proximity matrix value of 0.400 . Based on TPC and antioxidant activity value, it showed that samples with $100 \%$ fermented cocoa powder had the highest values with 
a value of $321.23 \mathrm{mg}$ GAE and $982.19 \mathrm{ppm}$, respectively. In this study, there is limited evidence to declare that cocoa drinks with the addition of unfermented cocoa powder will decrease the content of total phenolic and antioxidant compounds

\section{Acknowledgments}

This research has been funded by Ministry Education, Culture, Research and Technology, Indonesia, with contract number 163/E4.1/AK.04.PT/2021; 3487/LL3/KR/ $2021 ; 118 /$ SPK/LPP-UB/VII/2021 and Universitas Bakrie with contract number 133/ SPK/LPP-UB/VII/2021.

\section{REFERENCES}

Afoakwa, E.O. (2014). Cocoa Production and Processing Technology. Boca Raton: CRC Press.

Afoakwa, E.O.; J. Quao; F.S. Takrama; A.S. Budu \& F.K. Saalia (2012). Changes in total polyphenols, o-diphenols and anthocyanin concentration during fermentation of pulp pre-conditional cocoa (Theobroma cacao L.). International Food Research Journal, 19(3), 1071-1077.

Andriani, S.; M.R. Rakhmawati; D.D. Pratiwi \& F. Ariawan (2018). Analysis of consumers perception at the food court of Lampung Walk by using Multidimensional Scaling Approach. Al-Jabar Jurnal Pendidikan Matematika, 9(2), 209-219.

Andujar, I.; M.C. Recio; R.M. Giner \& J.L. Rios(2012). Review article: Cocoa polyphenols and their potential benefits for human health. Hindawi Publishing Corporation, 1-23.

Aprotosoaie, A.C.; S.V. Luca \& A. Miron (2016). Flavor chemistry of cocoa and cocoa products- An overview. Comprehensive Reviews in Food Science and Food Safety, 15, 73-91.

Borg, I. \& P. Groenen (2005). Modern Multidimensional Scaling: Theory and Applications $\left(2^{\text {nd }} e d.\right)$. Springer-Verlag, New York.
Delgado-Ospina, J.; C.D. Di Mattia; A. Paparella; D. Mastrocola; M. Martuscelli \& C. Chaves-Lopez (2020). Effect of fermentation, drying, and roasting on biogenic amines and other biocompounds in Colombian Criollo cocoa beans and shells. Foods, 9, 520, 1-20.

Hii, C.I.; S. Sharif; C.L. Law \& M. Jati (2009). Polyphenols in cocoa (Theobroma cacao L.). Asian Journal of Food and Agro-Industry, 2(04), 702-722.

Jalil, A.M.M. \& A. Ismail (2008). Polyphenols in cocoa and cocoa product: Is there a link between antioxidant properties and health ?. Molecules, 13, 2190-2219.

Kruskal, J.B. \& M. Wish (1977). Multidimensional Scaling. Sage Publications. Beverly Hills.

Kumar, S.; R. Sandhir \& S. Ojha (2014). Evaluation of antioxidant activity and total phenol in different varieties of Lantana camara leaves. BMC Research Notes, 7(560), 1-9.

Langkong, J.; M.M. Tahir; R.A. Nadja; S. Hidayat \& S.N. Sirajuddin (2020). Best formulation of cacao butter and powder for chocolate bar production. Eurasian Journal of BioSciences, 14, 3945-3949.

Moharram, H.A. \& M.M. Youssef(2014). Methods for determining the antioxidant activity: A review. Alex Journal Food Science \& Technology, 11(1), 31-42.

Mustafa, R.; A. Hamid; S. Mohamed \& F. Bakar (2010). Total phenolic compounds, flavonoids, and radical scavenging activity of 21 selected tropical plants. Journal of Food Science, 75, 28-35.

Purba, H.H.; M.S. Maarif, I. Yuliasih \& A. Hermawan (2018). Product development of chocolate with quality function deployment approach: A case study in SMEs chocolate industry in Indonesia. IOP Conference Series, Earth and Environmental Science 209 012011, 1-11.

Racine, K.C.; A.H. Lee; B.D. Wiersema; H. Huang; J.D. Lambert; A.C. Stewart \& A.P. Neilson (2019). Development and characterization of a pilot-scale model cocoa fermen- 
tation system suitable for studying the impact of fermentation on putative bioactive compounds and bioactivity of cocoa. Foods, 8(3), 120.

Ramlah, S. (2016). Karakteristik mutu dan citarasa cokelat kaya polifenol. Jurnal Industri Hasil Perkebunan, 11(1), 23-32.

Recio, M.C.; J.L. Rios \& R.M. Giner (2012). Cocoa polyphenols and their potential benefits for human health. Oxidative Medicine and Celullar Longevity, 1-21.

Sabahannur, St.; S. Alimuddin \& Rahmawati (2018). Changes in phenol level and antioxidant activity of cocoa beans during fermentation and roasting. Journal of Food Research, 7(4), 23-29.

Shahidi, F. \& P. Ambigaipalan (2015). Phenolics and polyphenolics in foods, beverages and spices: Antioxidant activity and health effects- A review. Journal of Functional Foods, 18, 820-897.
Singla, R.K.; A.K. Dubey; A. Garg; R.K. Sharma; M. Fiorino; S.M. Ameen; M.A. Haddad \& M. Al-Hiary (2019). Natural polyphenols: Chemical classification, definition of classes, subcategories, and structures. Journal of AOAC International, 102(5), 1397-1400.

Sudibyo, A. (2017). Effect of processing techniques on flavour and characteristics of cocoa processed and chocolate products. Jurnal Industri Hasil Perkebunan, 12, $1-13$.

Urbanska, B. \& J. Kowalska (2019). Comparison of the total polyphenol content and antioxidant activity of chocolate obtained from roasted and unroasted cocoa beans from different regions of the world. Moleculary Diversity Preservation International, 8(283), 1-13.<smiles></smiles> 